\title{
Self-Diagnosis of Head Lice Infestation in Rural Nigeria as a Reliable Rapid Assessment Tool for Pediculosis
}

\author{
Uade S. Ugbomoiko ${ }^{1}$, Rick Speare ${ }^{2}$ and Jorg Heukelbach ${ }^{*, 2,3}$ \\ ${ }^{I}$ Department of Zoology, University of Ilorin, Nigeria \\ ${ }^{2}$ Anton Breinl Centre for Public Health and Tropical Medicine; School of Public Health, Tropical Medicina and Reha- \\ bilitation Sciences, James Cook University, Townsville, Australia \\ ${ }^{3}$ Department of Community Health, School of Medicine, Federal University of Ceará, Brazil
}

\begin{abstract}
Pediculosis capitis is a common disease in industrialized countries, but there are also areas in sub-Saharan Africa where head lice infestations are highly endemic. However, there are no data available from the African continent on the accuracy of head lice diagnosis made by affected individuals.

We performed a door-to-door survey in Skanko village (Kwara State, Central Nigeria). Individuals were asked to answer a question regarding their head lice status, and then wet combing with conditioner was performed to diagnose an active infestation.

Active head lice infestation was observed in 144 (29.0\%) of the 496 participants. Less than $1 \%$ of those without pediculosis stated being infested; and more than $90 \%$ of individuals with heavy infections did so. In contrast, only $47 \%$ of individuals with $\leq 5$ lice were aware of their infestation. Overall sensitivity (73.6\%), specificity (99.1\%), positive predictive value $(97.2 \%)$ and negative predictive value $(90.2 \%)$ of self-diagnosis, as compared to wet combing were high.

Our data show that interviewing individuals about their infestation status can be used as a simple rapid assessment method for diagnosing head lice in a typical rural setting in Nigeria.
\end{abstract}

\section{INTRODUCTION}

In sub-Saharan Africa scarcity of resources and trained health personnel lead to neglect of minor parasitic diseases such as pediculosis capitis (head lice infestation). Pediculosis capitis is a common disease in industrialized countries $[1,2]$, but there are also areas in sub-Saharan Africa where pediculosis is highly endemic [3]. This fact has rarely been perceived by the scientific community, and consequently few studies are available from this region $[3,4]$.

Reasons for this are multi-faceted. A major reason is that due to poor access to health services and the presence of other more serious and life-threatening parasitic diseases, such as malaria, filariasis and schistosomiasis, pediculosis is usually not an issue justifying health interventions in subSaharan Africa, and is also not considered an important disease by health professionals (Ugbomoiko, unpublished data). Thus, an easy and accurate rapid assessment method is needed to diagnose pediculosis in communities where medical or paramedical resources are not available to assist.

Previous data from Brazil have shown that people in urban endemic communities diagnosed their head lice infestations with high positive predictive values (PPV) of $89 \%$ and $98 \%$, respectively $[5,6]$. However, in Australia, a developed market economy, sensitivity of parental diagnosis of

*Address correspondence to this author at the Departamento de Saúde Comunitária, Faculdade de Medicina, Universidade Federal do Ceará, Rua Prof. Costa Mendes 1608, 5. andar, Fortaleza CE 60430-140, Brazil;

Tel: 55-85-33668044; Fax: 55-85-33668045; E-mail: heukelbach@web.de head lice in children was very low (16\%), with a PPV of $67 \%$ [7]. Similarly, in Mexico schoolchildren selfdiagnosing pediculosis had a low sensitivity, even though they were asked about the presence of nits, and not of active infestations [8]. Unfortunately, in that paper an error was made in calculation of the epidemiological parameters, and predictive values were not given. Our recalculations using the original data give sensitivity of $46 \%$, specificity of $94 \%$, PPV of $68 \%$ and negative predictive value (NPV) of $86 \%$.

In the Brazilian study, the authors concluded that treatment of head lice infestations could be based on selfdiagnosis, and that there is no need for resource-intensive and unnecessary diagnosis by clinical inspection $[5,6]$. On the contrary, in Australia the conclusion was that parental reporting was not a reliable indicator of pediculosis [7]. This would also apply to the diagnostic accuracy of the Mexican schoolchildren.

Since there are no data available from the African continent on the accuracy of head lice diagnosis made by affected individuals or their guardians, we performed a populationbased study in a rural community in Nigeria where pediculosis is endemic, to determine sensitivity, specificity and predictive values of self-diagnosis, compared to combing with conditioner as the reference diagnosis.

\section{MATERIALS AND METHODS}

The study was conducted in Skanko village (Kwara State, Central Nigeria), a small rural community located about 140 $\mathrm{km}$ from Ilorin, the State's capital, with a population of 590 people. The villagers are predominantly illiterate and subsis- 
tence farmers, thus socio-economic and sanitary conditions are poor.

We performed a door-to-door survey which included all households in Skanko. After obtaining consent, the individuals present in each household were asked to answer a single question regarding their head lice status: "Do you have lice on your head?". The mere presence of nits was not asked for, as they do not prove active infestation. In the case of small children $(<7$ years of age), the parents acted as the information source. We then performed wet combing with conditioner to diagnose an active infestation, defined as the presence of adult lice or nymphs. Wet combing with conditioner is considered a sensitive method for diagnosing pediculosis [9]. The head was moistened with water, a commercially available hair conditioner was applied, and then the hair was combed with a fine-toothed plastic head lice detection comb of good quality. Previous studies had demonstrated a good quality plastic fine-toothed comb to be as effective as a metal toothed comb in removing adults and nymphs [10]. Each strike of the comb was skimmed on a clean white paper, until the conditioner was completely removed. The paper was examined for adult lice and nymphs, using a magnifying glass. The number of lice were counted and results arbitrarily grouped into light infection ( $\leq 5$ lice) and moderate or heavy light ( $\leq 5$ lice) and moderate or heavy ( $>5$ lice) infestations, respectively (Table 1). The response of individuals regarding their infestation status, stratified by parasite load, is presented in Table 1. Less than $1 \%$ of those without pediculosis stated being infested; and more than $90 \%$ of individuals with heavy infections did so. In contrast, only about half of individuals with $\leq 5$ lice were aware of their infestation (Table 1).

Overall sensitivity, specificity and predictive values were high and are given with their respective 95\% confidence intervals (Table 2).

\section{DISCUSSION}

Our data showed that self-diagnosis of active pediculosis in adults and in children by guardians can be used as an accurate rapid assessment method in this rural community in Nigeria.

A study by Anosike et al. (2007) in five states of Nigeria assessed clearance of pediculosis as an additional benefit of an ivermectin onchocerciasis control program [11]. They did not examine people for head lice, but relied on selfdiagnosis. This study adds confidence to their finding that the ivermectin program did in fact clear pediculosis.

Table 1. Relationship Between Number of Individuals or their Guardians Reporting Head Lice Compared with Lice Detected by Wet Combing, Stratified by Parasite Load

\begin{tabular}{|c|c|c|c|}
\hline Level of Pediculosis & Number Reporting Head Lice/Total & Percent Reporting Head Lice & Percent with Head Lice Detected of Total Surveyed \\
\hline \hline No lice detected & $3 / 352$ & $0.9 \%$ & - \\
\hline Light infestation $(\leq 5$ lice) & $27 / 58$ & $46.6 \% *$ & $11.7 \%$ \\
\hline Heavy infestation $(>5$ lice) & $79 / 86$ & $91.9 \% *$ & $17.3 \%$ \\
\hline Total & $108 / 496$ & $21.8 \%$ & $29.0 \%$ \\
\hline
\end{tabular}

infection ( $>5$ lice). If hair was plaited, plaits were opened before examination.

To avoid observation bias, interviews and wet combing were performed by different investigators. The investigator responsible for diagnosis was blinded to the response of the study participant.

Data were entered into an Excel spreadsheet, checked for entry-related errors and transferred to Epi Info version 6.04d (Centers for Disease Control and Prevention, USA). To describe the accuracy of self-diagnosis, sensitivity, specificity, positive predictive and negative predictive values were calculated from a $2 \times 2$ contingency table, with wet combing as the reference method, using the respective Epi Info Module.

The study was approved by the ethics committee of University of Ilorin, Kwara State, and in addition by traditional community leaders of the community. Study participants gave informed written consent. In case of illiteracy, individuals gave verbal consent and a thumb print.

\section{RESULTS}

In total, 496 individuals ( $84.1 \%$ of the target population) agreed to participate. Active head lice infestation was observed in $144(29.0 \%)$ participants, $11.7 \%$ and $17.3 \%$ with
Table 2. Sensitivity, Specificity and Predictive Values of SelfDiagnosis, as Compared to Wet Combing

\begin{tabular}{|c|c|}
\hline & \% (95\% Confidence Interval) \\
\hline \hline Sensitivity & $73.6 \%(65.5-80.4)$ \\
\hline Specificity & $99.1 \%(97.3-99.8)$ \\
\hline Positive predictive value & $97.2 \%(91.6-99.3)$ \\
\hline Negative predictive value & $90.2 \%(86.7-92.9)$ \\
\hline
\end{tabular}

Rapid assessment methods using self-diagnosis have been used for a limited number of parasitic diseases with distinctive signs, such as haematuria in urinary schistosomiasis $[12,13]$. Diseases that can be reliably self-diagnosed enable health personnel and community health workers in affected populations to collect epidemiological data about the prevalence of a disease in a cost-effective manner [11]. In addition, self-diagnosis of pediculosis in this region could be a basis for treatment of head lice infestation without confirmation by health care personnel.

The value of self-diagnosis of pediculosis varies greatly with geographic location and population [5-8]. However, in 
all studies (Mexico, Brazil, Australia and the current study from Nigeria), sensitivity was lower than specificity and predictive values. Sensitivity in the Australian population was so low $(16 \%)$ as to make self-diagnosis of limited value as a cost-effective survey tool. In all studies, however, specificity was high as was NPV.

\section{CONCLUSION}

We have shown that interviewing individuals about their infestation status can be used as a simple rapid assessment method for diagnosing head lice in a typical rural setting in West Africa.

\section{ACKNOWLEDGEMENTS}

We thank the students involved in field work and the study participants for their cooperation. The study was partly supported by a PROÁFRICA grant from the Conselho $\mathrm{Na}$ cional de Desenvolvimento Científico e Tecnológico $(\mathrm{CNPq} / \mathrm{Brazil})$. J.H. is research fellow from $\mathrm{CNPq}$.

\section{REFERENCES}

[1] Heukelbach J, Walton SF, Feldmeier H. Ectoparasitic infestations. Curr Infect Dis Rep 2005; 7: 373-80.

[2] Burgess IF. Human lice and their management. Adv Parasitol 1995; 36: $271-342$.

[3] Govere JM, Speare R, Durrheim DN. The prevalence of pediculosis in rural South African schoolchildren. S Afr J Sci 2003; 99: 21-3.
$1-4$

[5] Heukelbach J, Kuenzer M, Counahan M, Feldmeier H, Speare R. Correct diagnosis of current head lice infestation made by affected individuals from a hyperendemic area. Int J Dermatol 2006; 45: 1437-8.

[6] Pilger D, Khakban A, Heukelbach J, Feldmeier H. Self-diagnosis of active head lice infestation by individuals from an impoverished community: high sensitivity and specificity. Rev Inst Med Trop Sao Paulo 2008; 50: 121-2.

[7] Counahan ML, Andrews RM, Speare R. Reliability of parental reports of head lice in their children. Med J Aust 2005; 182: 137-8.

[8] Paredes SS, Estrada R, Alarcon H, Chavez G, Romero M, Hay R. Can school teachers improve the management and prevention of skin disease? A pilot study based on head louse infestations in Guerrero, Mexico. Int J Dermatol 1997; 36: 826-30.

[9] De Maeseneer J, Blokland I, Willems S, Vander Stichele R, Meersschaut F. Wet combing $v s$ traditional scalp inspection to detect head lice in schoolchildren: observational study. BMJ 2000; 321: 1187-8.

[10] Speare R, Canyon DV, Cahill C, Thomas G. Comparative efficacy of two nit combs in removing head lice (Pediculus humanus var. capitis) and their eggs. Int J Dermatol 2007; 46: 1275-8.

[11] Anosike JC, Dozie IN, Ameh GI, et al. The varied beneficial effects of ivermectin (Mectizan) treatment, as observed within onchocerciasis foci in south-eastern Nigeria. Ann Trop Med Parasitol 2007; 101: 593-600.

[12] Guyatt H, Brooker S, Lwambo NJS, Siza JE, Bundy DA. The performance of school-based questionnaires or reported blood in urine in diagnosing Schistosoma haematobium infection: patterns by age and sex. Trop Med Int Health 1999; 4: 751-7.

[13] Lengeler C, Utzinger J, Tanner M. Questionnaires for rapid screening of schistosomiasis in sub-Saharan Africa. Bull World Health Organ 2002; 80: 235-42.

Received: October 13, 2008

(C) Ugbomoiko et al.; Licensee Bentham Open.

This is an open access article licensed under the terms of the Creative Commons Attribution Non-Commercial License (http://creativecommons.org/licenses/by$\mathrm{nc} / 3.0 /$ ) which permits unrestricted, non-commercial use, distribution and reproduction in any medium, provided the work is properly cited. 